\title{
الدليل الاستقرائي بين ديفيد هيوم وبرتراندرسل
}

أ. سميرة سالم القويري

جامعة مصراتة

\section{مقدمة:}

يُعد المنهج التجريبي الذي جاء به الفلاسفة المحدثون ثورة على المنطق الأرسطي،

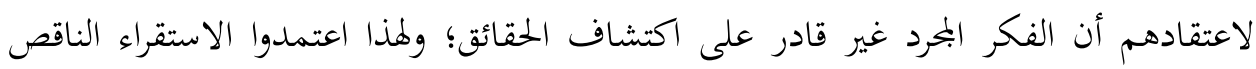
الذي يقوم علي الملاحظة والتجربة، متخذين من قانون العلية دليلاً استقرائيّا للمنهج التجريبي. وقد كان لديفيد هيومَ بهذا الصدد تفسير عبر به عن موقفه بتحاه هذا الدليل الاستقرائي المتمثل في العِلِّة، جعله أول فيلسوف أوروبي نقل فكرة العلية أو السببية من معانيها الأرسطية إلى معنى التتابع المحرد؛ هذا التتابع لا يعني شيئًا أكثر من أن العلة أو السبب سابقة على المعلول

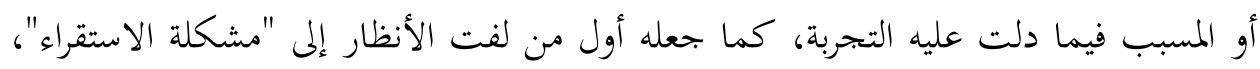

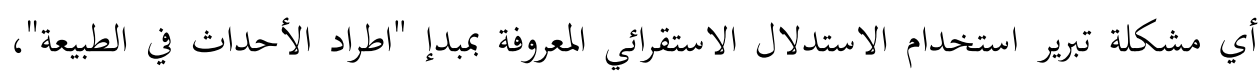
حيث أشار إلى أن نتيجة الاستدلال الاستقرائي ليست قضية من القضايا الرياضية أو المنطق، أي ليست قضية تحليلية، ومن تَمَّ فإِنكار نتيجة الاستدلال الاستقرائي لا يوقعنا في تناقض.

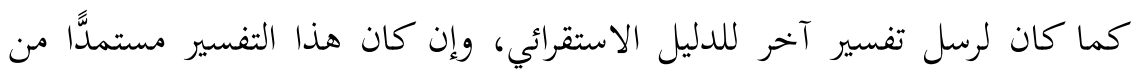
هيوم، فإن رسل استفاد في صياغته من مواقف العلماء المعاصرين؛ وكان يطوره بتطور نتائج علم

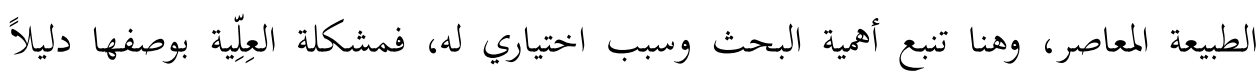

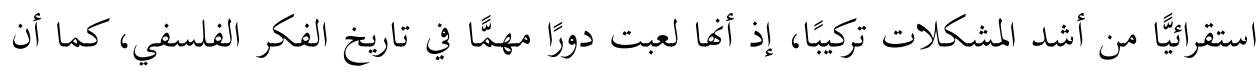
إنكار هيوم لضرورة العلاقة بين العلة والمعلول وضع الفكر أمام أزمة حقيقية عرفت بمشكلة الاستقراء، بالإضافة إلى أن تفسير رسل لهذه المشكلة أدى به إلى مزج النظرة الفلسفية بالنظرة

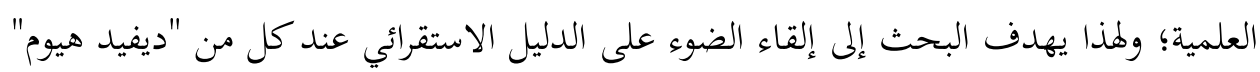

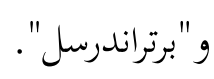


وقد اتبع البحث المنهج التحليلي المقارن على المستوى الأفقي الذي سأقوم من خلاله بتحليل آراء كل من: "هيوم" و "رسل" على حده بصدد تفسير الدليل الاستقرائي، ثم أحاول في الخاتمة بيان أوجه الاتفاق والاختلاف بين من الفيلسوفين رسئ في هذا الصدد. أولاً. الاستقراء لغةً واصطلاحًا:

الاستقراء لغة: يعني التتبع، من استقرأ الأمر، إذا تتبعه لمعرفة أحواله (1).

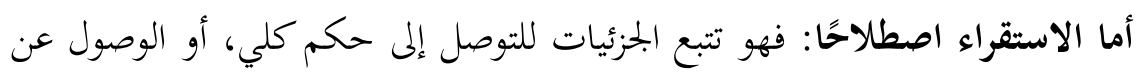

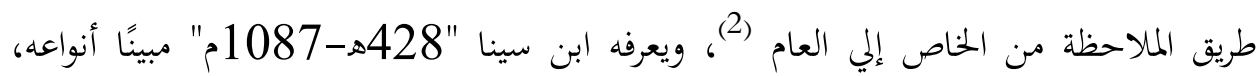
بقوله: (( هو حكم علي كلى لوجود ذلك الحكم في جزئيات ذلك الكلي، إما كلها و هو الاستقراء التام، وإما أكثرها و هو الاستقراء المشهور ))، ومن هنا نرى أن ابن سينا قد أقام الاستقراء الاستدلالي علي أساس من تعدد الحالات، فما كان شاملاً لها عدة استقراءً كاملاً، وما كان أقل عددًا منها كان ناقصًا (3).

ويسمى الاستقراء الناقص Incomplete induction الاستقراء غير التام، وهو انتقال غير يقيني من الحكم على الحالات الجزئية المشاهدة إلى الحكم على كل الحالات الممكنة التي شاهدناها والتي لم نشاهدها، وهو استدلال تعميمي معرض للسقوط والتغيير، مهما كثرت التهات

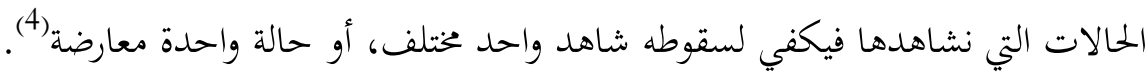

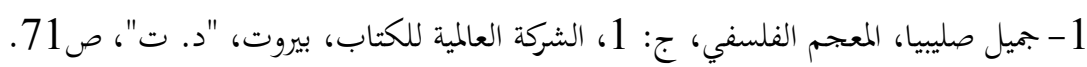

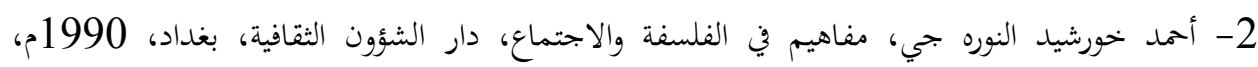
ص 30

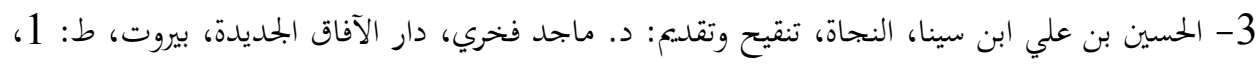

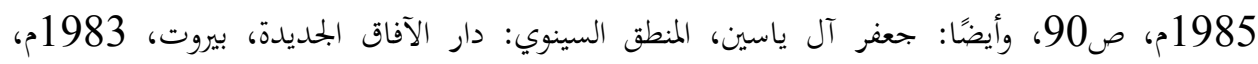
.76 4- محمد أحمد السرياقوسي، التعريف بمناهج البحث المنطقي، دار الثقافة للنشر والتوزيع، القاهرة، 1995م، ص54. 
وقد اعتمد التجربيون مبدأ العلية دليلاً استقرائيًا، ومبدأ العلية ليس نظرية علمية بحريبية

عامة، وإنما هو قانون فلسفي عام تقضي به الضرورة العقلية. أما التفسير العلمي للظواهر الطبيعية فيقول إن الظواهر الطبيعية متوقفة على العلل، إما

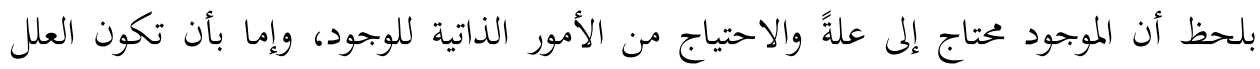
متوقفة على الحدوث أو الإمكان الذاتي أو الإمكان الوجودي.

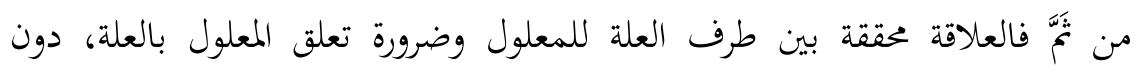
المقارنة بينهما، والتقدم بينهما بالطبع لا في مرحلة الزمان، وقد ذهب هيوم في تعريف العلة إلى أن العلة عبارة عن كوفها حادثة متقدمة والمعلول حادثة متأخرة (1). وعليه فالكون لابد أن يخضع لقانون السببية والعلية؛ لعدم إمكان الوجود من غير علة، وهو ما يعبر عنه بقانون الحتمية. ويكمن الفرق بين العلة والسبب في أن: 1. العلة: الغرض منها ملاحظة الإيجادية والموجودية بنحو الكفاءة الذاتية، مثال ذلك بك بك

$$
\text { "خالقية المبدأ الأعلى للوجودات الكونية ". }
$$

2. السبب: يراد منه جهة الاشتراك في التأثير،سواء كان لمعونة العلة أم الشروط، ومثال

أ. تأثير السبب استقلالاً، كالإحراق بالقياس إلى النار.

ب. التأثير منضمًا إلى بعض الشروط الأخرى، كتحليق الطائرة عند امتلائها بالمواد

$$
\text { المحرقة مع ضغط الزر على الجهاز المحرك (2). }
$$

1 - محمد محمد طاهر آل شبير، نقد المذهب التجريب، دار ومكتبة الهلال، بيروت، 1987م، ص222 - 
والعلية -بوصفها مبدأ من مبادئ العلم الحتمي- تؤكد تناسق الطبيعة وانتظامها، فإذا

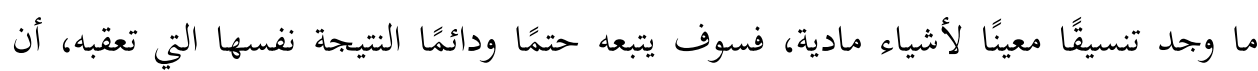

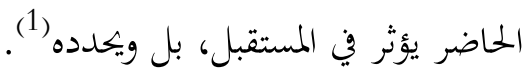

\section{ثانيًا. الدليل الاستقرائي عند "ديفيد هيوم":}

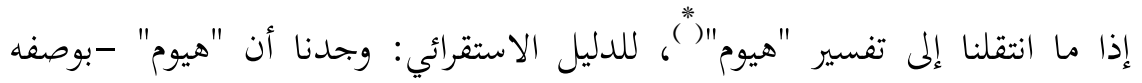
فيلسوفًا اختباريا- رد المعرفة البشرية إلى أصول اختبارية، رأى أن الأساس الوحيد لعلم الإنسان ينبغي أن يقوم على التجربة والملاحظة؛ ولذلك فهو لم يتجاوز حدود التجربة حيث يقول:

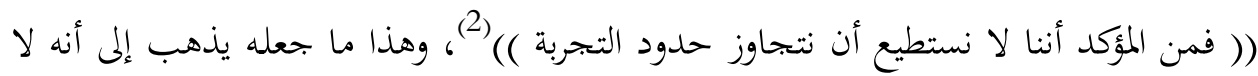
يمكن أن نعرف ماهية الأشياء سواء أكانت مادية أم روحية؛ لأن ذلك يقع خارج متناول

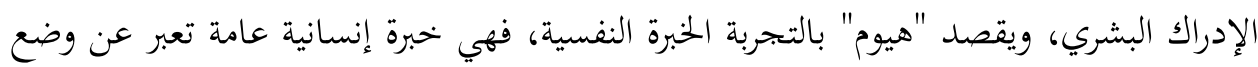

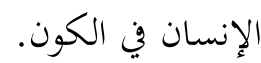
رد "هيوم" المعرفة إلى إدراكات العقل التي تنحل إلى نوعين متمايزين هما: الانطباعات

الحسية والأفكار.

1 - يمنى طريف الحولي، العلم والاغتراب والحرية، الهيئة المصرية العامة للكتاب، القاهرة، 1987م، ص55. (*) ديفيد هيوم "1711م-1776م"، فيلسوف إسكتلندي، ومؤرخ وأدب، أهم مؤلفاته: رسالة في الطبيعة

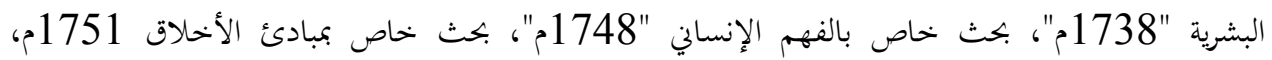

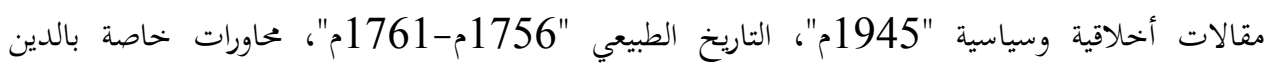
الطبيعي، وقد نشر بعد موته.

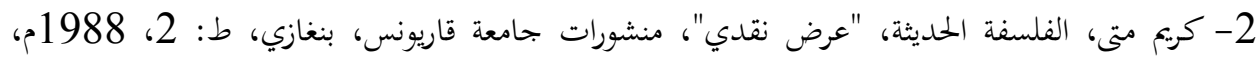

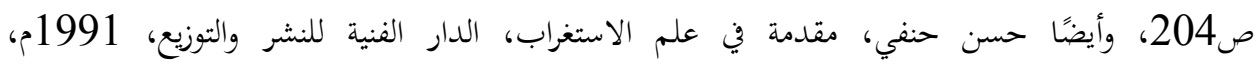
ص300. 
1. الانطباعات الحسية المباشرة: هي الإدراكات التي تدخل العقل أشد قوة وعنغًا للمرة

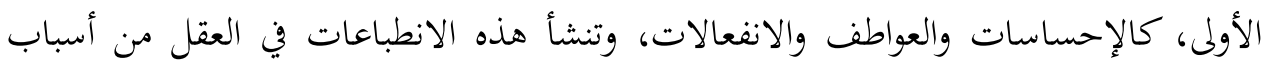
(1) بحهولة (1)

2. أما الأفكار: فهي صور باهتة من الانطباعات، والأفكار نوعان:

أ. أفكار الذاكرة: وهي صورة مطابقة لما نشأت عنه من انطباعات.

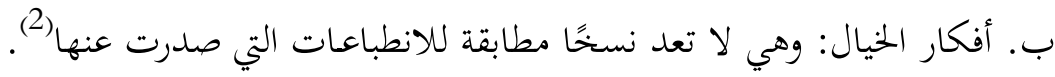

والانطباعات -فيما يرى هيوم- أكثر وضوحًا وأقوى أثرًا من الأفكار؛ ودليله على ونى لئل

ذلك أن الانطباع الحسي يكون واضحًا أثناء مباشرته وممارسته، ويكون ضعيفًا حين تستعيده الذاكرة، ووفقًا لهيوم لكي يحدث الانطباع وتتكون الفكرة، لابد للحاسة أن تقع على شيء معين؛ ولذلك فهو يقول: (( إن من حُرم حاسة حُرم الأفكار التي يمكن أن تتركب من

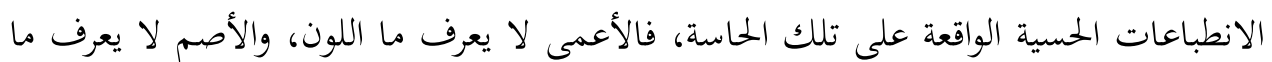

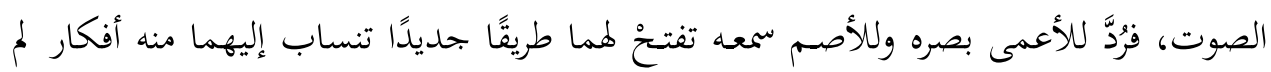

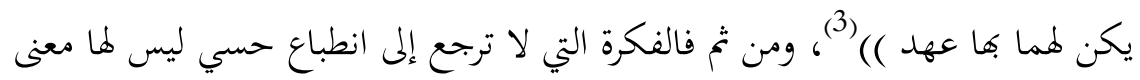
ويذهب هيوم إلى أن الأفكار المركبة تتكون من ترابط الأفكار البسيطة بعلاقات خاصة ترجع إلى قانون "تداعي الأفكار والانطباعات الحسية"، الذي استنبطه من ملاحظة الظواهر النفسية،وهي ثلاث علاقات: 1. التشابه: فالفكرة المعينة تستدعي زميلتها إذا كان بينهما تشابه، فرؤيتك صورة تستدعي إلى ذهنك صاحب الصورة، لما بين الأصل والصورة من تشابه.

$$
\text { 1- - حسن حنفي، مقدمة في علم الاستغراب، ص300. }
$$

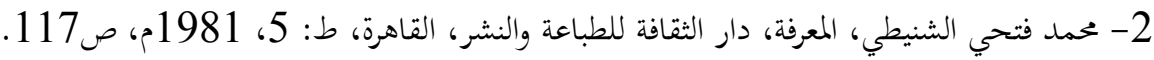

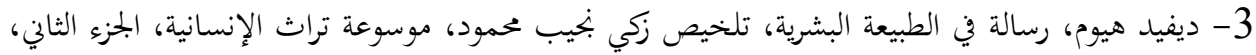

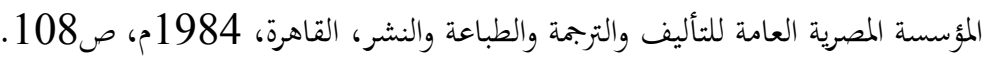


2. التجاور في الزمان والمكان: فالفكرة تستدعي زميلتها إذا وقعتا معًا في لحظتين

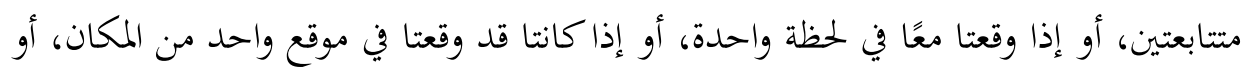
في موضعين متقاربين، فذكرك مسكنا يستدعي المسكن الذي يجاوره، لما بينهما من بتحاور مكاني.

3. العلة والمعلول: فالفكرة تدعو فكرة أخرى إذا كانت علة لها أو معلولة لها، فتفكيرك

في جرح يستلزم تفكيرك في الألم الذي يصاحبه، لما بينهما من علاقة العلة بمعلوها(1).

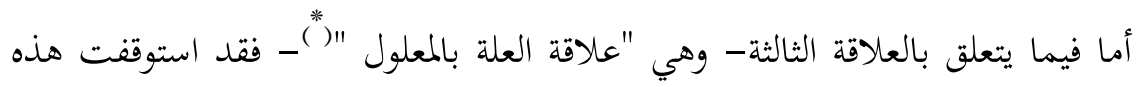
العلاقة هيوم؛ حيث رأى أن التعميم الاستقرائي بأن هناك علاقة ضرورية بين العلة والمعلول، وأن

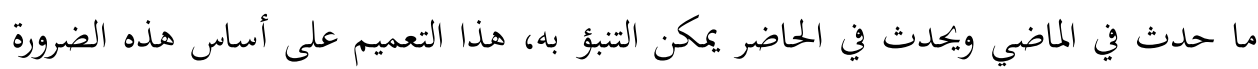
لا يشكل اليقين.

ولذلك رأى أن مبدأ الاستقراء في حاجة إلى شيئين هما:

1. لابد أن نضمن سلامة قانون العلية بأنه صحيح، وبأن العلاقة بين الاثنين علاقة

ضرورية.

2. أن نضمن أن الطبيعة تسير على المنوال نفسه، وأن ما حدث في الماضي يحدث في

الحاضر وسيحدث في المستقبل.

وهذا -بدوره- يتطلب توفر ثلاثة شروط في العلية وهي:

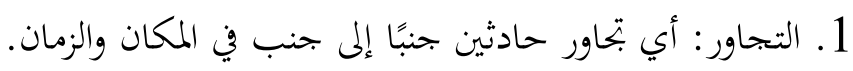

1- ديفيد هيوم، رسالة في الطبيعة البشرية، ص110، وأيضًا: فتحي الشنيطي: المعرفة، ص 118. (*) كان للإمام الغزالي "1058م- 1111م" رأي في السببة سبق به هيوم، فالعلاقة السببية لا تزيد على تتابع بين السبب والمسبب، وهي ليست ضرورية محتومة بحكم العقل؛ بل هي تتابع يقع في التجربة ونتعوده،

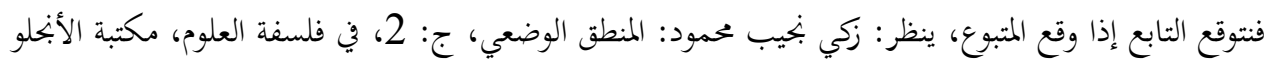

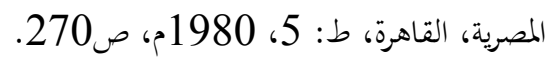


2. الأسبقية: أي لابد للعلة أن تسبق المعلول، ولا يمكن العكس.

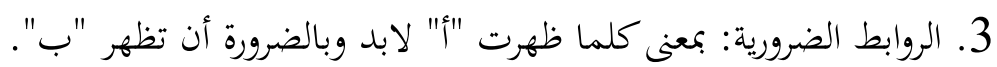

وهنا لاحظ هيوم أن الشرطين "الأول" و"الثاني" متوفران في العلاقات بين الأشياء الخارجية، ولا نكاد بحد الشرط الثالث بين العلاقات؛ ولهذا السبب رفض هيوم أن تكون العلاقة

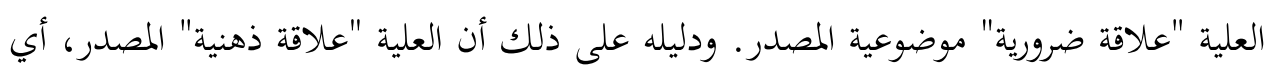
ذاتية وليست موضوعية؛ وذلك لأن ترابط فكرتين في الذهن بعد بحاورهما في المكان والزمان وتكرار حدوثهما يولد عادة اكتسبت من القوة والحيوية، فتحولت فينا إلى اعتقاد، وهذا الاعتقاد هو الذي يسوغ هذه العلاقة، ومن ثم فالانطباع يسبق الفكرة، لكنهما يقترنان في المكان والزمان، كما أن هذا الاقتران "ذهني ذاتي" وليس "منطقيَّا موضوعيًا" (1).

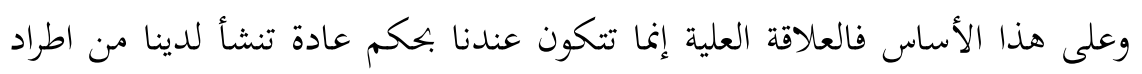
الارتباط بين الحادثة الأولى والحادثة الثانية اطرادا يجعلنا إذا ما وقعت الحادثة الأولى نتوقع حدوث الثانية، ودون أن تكون هنالك ضرورة عقلية تقتضي ذلك. إنما التجربة وحدها هي التي تدلنا

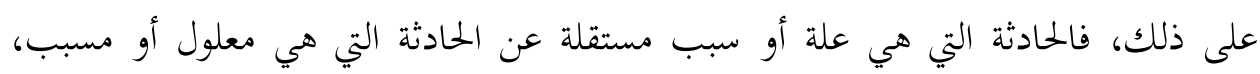
وتحليل إحداهما لا يدل على الأخرى، فحركة الكرة الثانية من كرتي البلياردو حادث قائم بذاته بالنسبة إلى حركة الكرة الأولى؛ وليس في أي من الحركتين أقل علامة تشير إلى ضرورة وجرد إلى

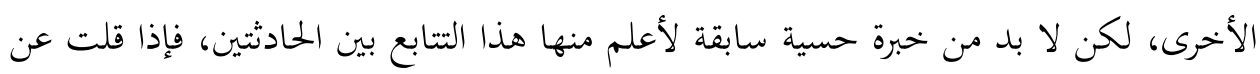

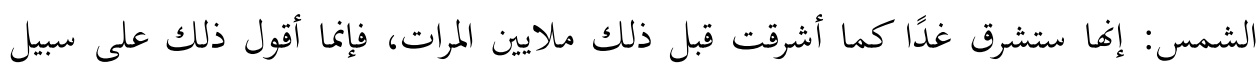
الترجيح، وهذا الترجيح والاحتمال لا يتضمن تناقض العقل مع ذاته؛ ومن ثم فالخبرة الحسية لا التفكير العقلي الخالص - هي المصدر الذي نستقي منه علمنا بالواقع، ودوها يستحيل التنبؤ بما يحدث من حوادث في عالم الواقع (2).

1 - كريم متى، الفلسفة الحديثة، ص216، 217.

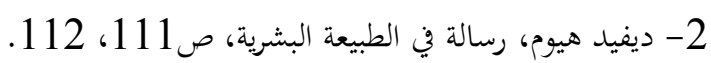


والموقف الذي انتهى إليه هيوم من مناقشة فكرة العلية ومبدأ اطراد الأحداث في

الطبيعة هو: أن تصور العلية مكتسب من الخبرة وليس قبليًا، إذ أنه لا يمكننا أن نتوقع حدوث المستقبل على غرار الحاضر والماضي؛ لأن العلاقة العلية استحالت بعد التحليل إلى علاقة بين سابق ولاحق أساسها العادة، والحواس هي التي تكشف عن طبيعة هذه العلاقة من واقع الخبرة. أما فيما يتعلق بمبدأ اطراد الأحداث في الطبيعة Uniformity of Nature، فليس

لدينا دليل لتبرير الاعتقاد بهذا المبدأ؛ أي ليس لدينا تبرير من الخبرة الحسية يعد معيارًا بحريبيا يقرر صدق القوانين العلمية التي نتوصل إليها من عدد من الحوادث التي لوحظت في الماضي أو الحاضر، ولذا فإنه لا يمكننا تقرير أن المستقبل سيكون على غرار الحاضر أو الماضي، حيث ليس لدينا برهان لإثبات الاطراد بتريبيًا دون أن نقع في الدور (1). ثالثًا. الدليل الاستقرائي عند "بوتراندرسل":

إذا ما انتقلنا إلى تفسير "برتراندرسل"(") للدليل الاستقرائي: وجدنا أن موقف "رسل" لرسل بهذا الصدد قد تطور بتطور نتائج نظريات علم الطبيعة المعاصر، ولذا ربط العلية بموضوعات الاستقراء والحتم واللا تعين ومصادرات البحث العلمي.

2- ماهر عبد القادر محمد، فلسفة العلوم، "المشكلات النظرية والتطبيق"، دار المعرفة الجحامعية، الإسكندرية، 1997م، ص 98، 101، 102

(*) يعد الفيلسوف الإنحليزي برتراندرسل "1872-1970م" إمام التحليل المنطقي وداعية الفلسفة العلمية في القرن العشرين، أراد للفلسفة أن تتقدم على طريقة جاليليو الفيزيائية بالاكتفاء إلى الوصول إلى نتائج جزئية تقبل

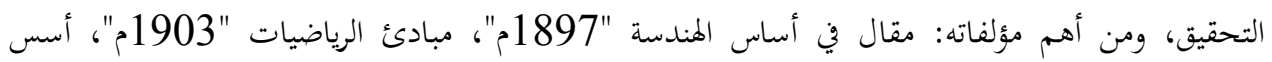

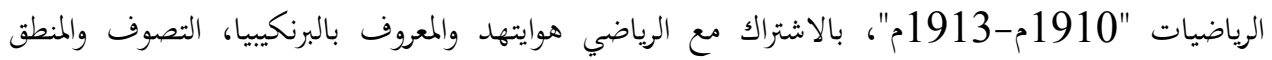

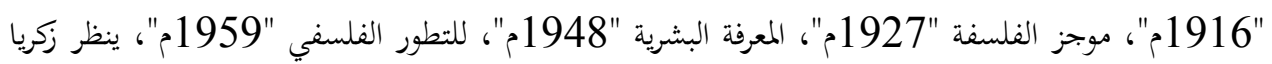

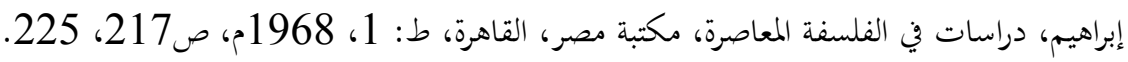
292 


\section{1 - ملاقة العلية بالاستقراء:}

يعرف رسل في كتابه "أصول الرياضيات" "1903م" العلية Causality بأها (( المبدأ الذي بمقتضاه يمكن استنتاج حادثة أو أكثر في لحظة جديدة أو أكثر من عدد كافِ من إِ اللحظات () (1) وقد حاول رسل هنا أن يقيم علاقة بين مفهوم العلية وقوانين الحركة مدللاً على ذلك بمبدأين في الديناميكا هما: أ. إن علاقة العلية تقوم بين حوادث في ثلاثة أوقات لا اثنين.

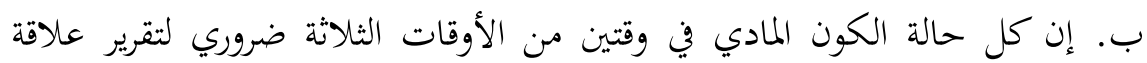
العلية. ومعنى ذلك أن رسل يرفض علاقة ثنائية للعلية "أ - ب" مثلاً، ويقترح علاقة ثلاثية الأبعاد، عندما يجتمع بُعدان منها فإِهما يؤديان إلى الثالث لا محالة، والعلاقة العلية هنا علاقة تقريبية وليست محكمة، كما أهما تقوم بين طوائف؛ بمعنى أن طائفة من الحوادث القائمة ترتبط ارتباطاً

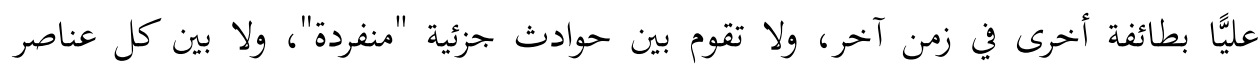
الحالة الحاضرة، وكل عناصر الحالة التالية (2. هذا، وقد تناول رسل في كتابه "مشكلات الفلسفة" "1912م" "مشكلة الاستقراء" المتمثلة في اطراد وقوع الحوادث الطبيعية من خلال مناقشته مسألة "شروق الشمس Sunrise" - كمثال توضيحي as an illustration وهي مسألة لا يشعر احد منا بأقل شك فيها، فنحن متفقون على أن الشمس سوف تشرق غدًا، لأهما كانت تشرق في الماضي وتشرق دائمًا

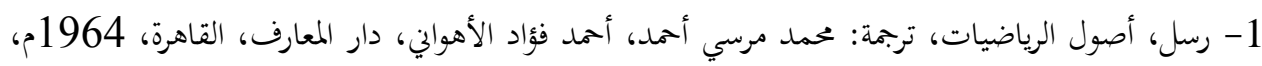

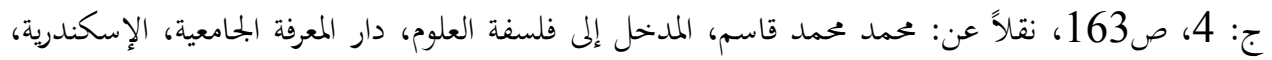

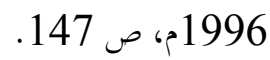
2- 2 - المرجع السابق، ص ص 147 147، 149. 
كل يوم. ومثل هذه التوقعات -في رأي رسل - محتملة فقط، بيد أن غرائزنا بتعلنا على يقين من أن الشمس سوف تشرق غدًا، ولهذا يجب علينا -ونخن بصدد هذه المشكلة- إن نميز تمييزًا مهما بين حقيقة أن الاطراد في وقوع الحوادث يسبب توقعات في المستقبل، وبين مسألة ما إذا كان هناك أساس معقول لأن نقيم وزنًا لمثل هذه التوقعات (1). ووفقًا لرسل فإن الاعتقاد في وقوع الحوادث في الطبيعة هو الاعتقاد في أن كل شيء قد حدث أو سيحدت هو حالة لقانون عام GENERAL LAW لا استثناءات له، أما التوقعات الساذجة THE CRUDE EXPECTATIONS تؤدي للوقوع في الخطأ. فالاعتقاد بأن الشمس سوف تشرق غدًا يمكن أن يكذب إذا اصطدمت فئاء الأرض فجأة بجسم ضخم يفسد أو يحطم دوراها IT'S ROTATION، لكن قوانين الحركة

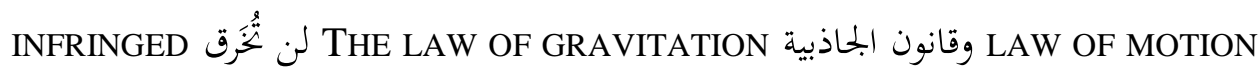
بمثل هذا الحدث، لأفها ليست خاضعة لهذه الاستثناءات؛ ولهذا فإن ما ينبغي أن نبحث عنه هو

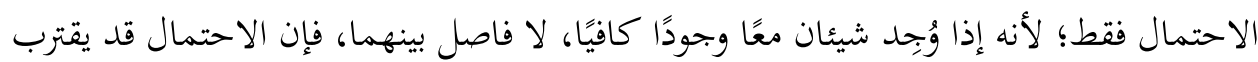

$$
\text { من مرتبة اليقين، لكنه لن يصل أبدًا إلى مرتبة اليقين (2). }
$$

ولضمان صحة وتبرير قيام القوانين العلية في المستقبل على نحو ترجيحي احتمالي، قال رسل

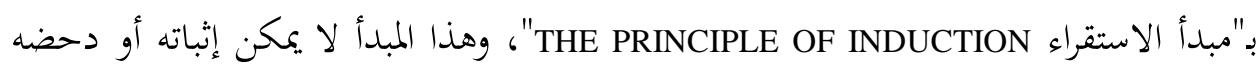
عن طريق التجربة، وهو (( وحدة القادر على تبرير أي استدلال، مما تم فحصه على ما لم يتم

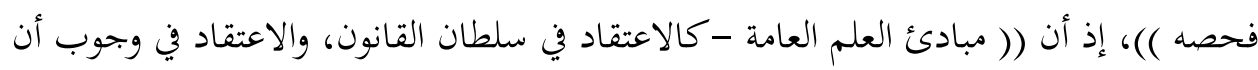
يكون لكل حدث سبب - تعتمد على مبدأ الاستقراء بقدر ما تعتمد عليه إعتقادات العاد الحياة (اليومية () (3) (بكون (3)

1- B, Russell: the problems of philosophy Oxford University Press London, 2001, pp. $33: 35$

2 -.I bid, pp. 35,36

3 - B, Russell: the problems of philosophy, p 38. 
وهذا المبدأ الاستقرائي - فيما يرى رسل - مبدأ عقلي لم نستمده من التجربة، يقول إن ما

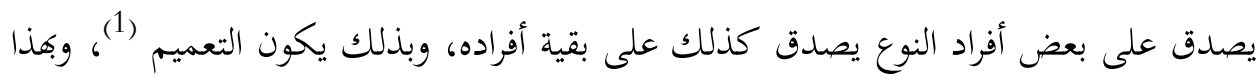

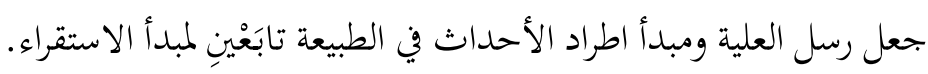

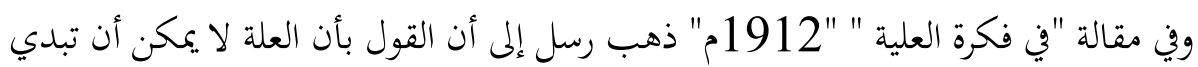
أي تأثير في أي مكان ما عدا المكان الذي توجد به، هو حكم بلا مبرر، ومعنى هذا أن رسل كان يقبل فكرة التأثير عن بعد بما تنطوي عليه من مفاهيم علية، كما قدم -فيما يتعلق بالعلاقة العليةنوعًا أسماه علاقة تكهن "قبل - علمية" PRE- SCIENTIFIC تقوم بين حوادث متصلة وإن كانت هذه الحوادث غير محددة بدقة، مثل وضع عملة معدنية في آلة تعمل بوضع النقود، وتشير العلاقة

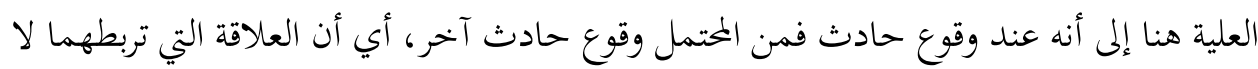
تتصف بالضرورة، أما فيما يتعلق باستدلالاتنا حول المستقبل، فقد ظلت تتخذ عند عنده من من مبدأ

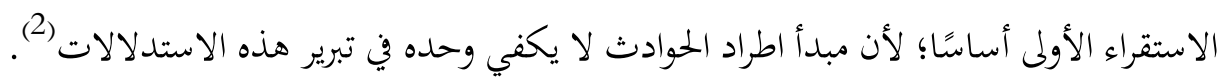

\section{2 2 العلية والحتمية:}

رفض رسل مبدأ العلية بالمعنى التقليدي الذي يقتضي أن لكل حادثة فردية علة هي الأخرى حادثة فردية، واعترف في كتابة " معرفتنا بالعالم الخارجي كميدان لممارسة المنهج العلمي في الفلسفة " "1914م" بتضاؤل تطبيق مبدأ العلية في قوله: إن المبدأ القائل (( إن نفس العلة تؤدي إلى نفس المعلول يعد ذا بحال ضيق عما يحدث في العالم بالفعل )(3).

1- زكي بخيب محمود، المنطق الوضعي، ج: 2، "في فلسفة العلوم"، مكتبة الأنحلو المصرية، القاهرة، ط: 5،

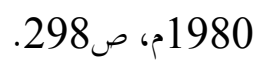

2- محمد محمد قاسم، مدنحل إلى فلسفة العلوم، ص150، 150، 151. 3 - B, Russell: our knowledge of the External world, p216. نقلاً عن، محمد محمد قاسم، المدخل إلى فلسفة العلوم، ص152، وأيضًا: محمود فهمي زيدان، من نظريات

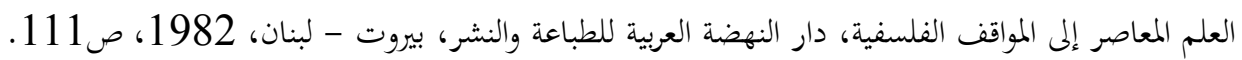


رأى رسل أن مبدأ العلية يجد تطبيقه التجريبي حين بجد بحموعتين من الحوادث، ويأخذ بالحوادث بالمعنى الوارد في النظرية العامة للنسبية لأينشتين التي تنادي بالحتمية المعتدلة؛ فالحوادث

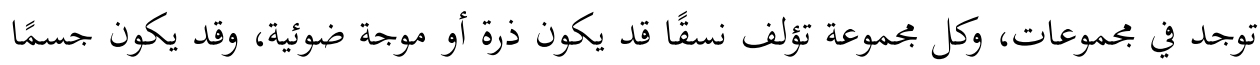

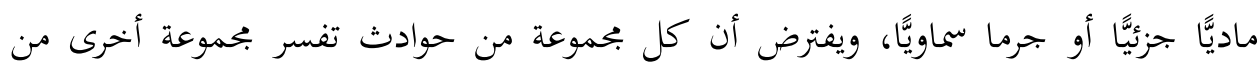

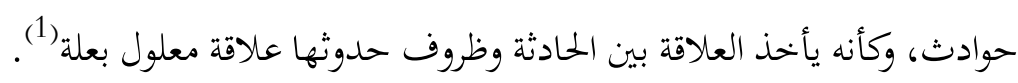

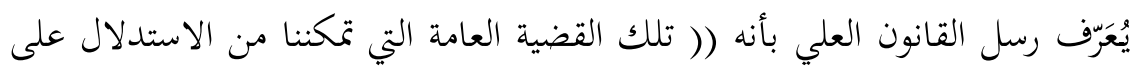

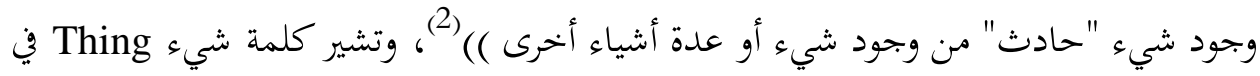
هذا التعريف إلى كل ما هو جزئي يتميز بواقعية موضوعات الحس. والأشياء - سواء كنا نستدل

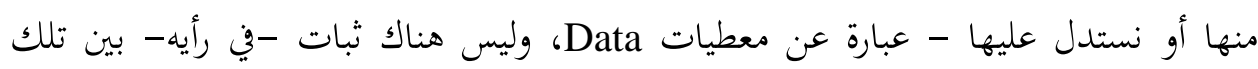
المعطيات من حيث الأثر والتأثر، بل إن ما هو ثابت هو العلاقة بين ما هو معطى وما هو مستتتج، أما بالنسبة للعلة والمعلول أو الأثر والنتيجة فيمكن أن يسبق الأول الثاني كما هو الحال

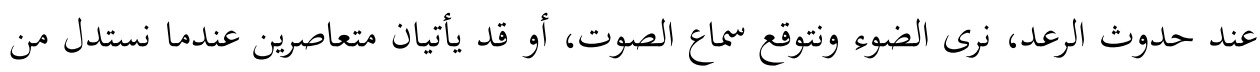

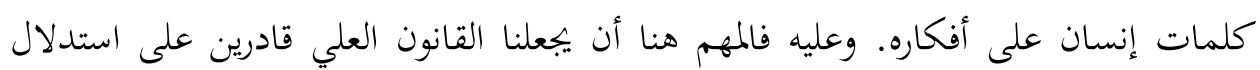
وجود شيء ما نستطيع أن نصفه بدقة في ألفاظ المعطيات ذاتا (3).

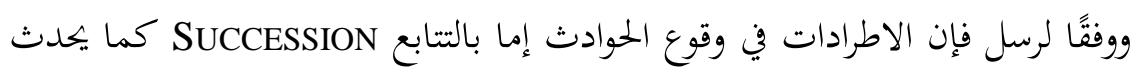
الرعد بعد البرق، والدفء بعد الاقتراب من النار، أو بالتصاحب COMPRESENCE كما هو ولهو الحال بين اللمس والرؤية. هذه الاطرادات تجعلنا نتوقع حدوثها في المستقبل على الوتيرة نفسها. ويسمى رسل هذا التوقع بالاعتقاد الحيواني للعلية (4).

1- محمود فهمي زيدان، من نظريات العلم المعاصر إلى المواقف الفلسفية، ص111، 112. 2- B, Russell: our knowledge of the External world, p215.

نقلاً عن: محمد محمد قاسم، المدنحل إلى فلسفة العلوم، ص152.

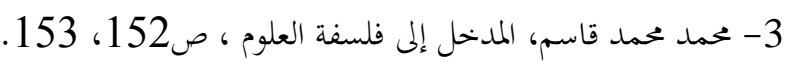

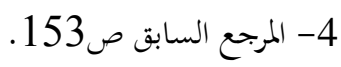


يشير رسل إلى أن قانونًا ما لا يعد صادقًا في حالة عدم انطباقه على جميع أمثلته أو وقائعه، ومن ثم تصبح الحاجة ملحة إلى قانون أعم وأشمل من سابقه، وقد أدى تحمس رسل واعتقاده المفرط في القوانين العلية العلمية إلى ميل نحو الاعتقاد بنوع من الحتمية؛ فأسس قيام القوانين العلية في رأيه أكثر رسوخًا في العلم عنها في حياتنا اليومية وعلم النفس. أما بالنسبة للدليل على استمرار القوانين العلية في المستقبل فهو - فيما يرى رسل رسلي - مبدأ الاستقراء بوصفه القانون القبلي المنطقي الذي يكفل لنا أن نستنتج احتمال القوانين العلية في المستقبل، ودونه يستحيل الاستدلال على وجود شيء لا نشاهده بطريقة مباشرة ( 1 ) . ورسل هنا يؤكد ما قاله في كتابه "مشكلات الفلسفة" من أن أهمية مبدأ الاستقراء تفوق أهمية قانون العلية ذاته.

\section{3. العلية واللاتعيُّن:}

في كتاب "تحليل العقل" "1921م" تحدث رسل عن نظرية الواحدية (") المحايدة NEUTRAL MONISM العقل والمادة تركيبان منطقيان له لعناصر أولية ليست في ذاتحا عناصر عقلية ولا مادية، تتميز المادة عن العقل بأن عناصر معينة فقط مثل الصور والمشاعر تدخل في تكوين العقل وفقًا لقوانين علية مختلفة؛ ومن تم فإن مدركات معينة تكون موضوعات فيزيقية - متى تحمعت وفقًا لقوانين الفيزياء

$$
\text { 1- 1 - المرجع السابق ص154، } 155 .
$$

(*) تقول أن العقل والمادة مشتقان من "هيولي" محايدة لا هي عقل ولا مادة، لكن أجزاءها إذا ارتبطت بمجموعة معينة من العلاقات أسميناها عقلاً، وإذا ارتبطت بحموعة أخرى من العلاقات أسميناها مادة، والحوادث

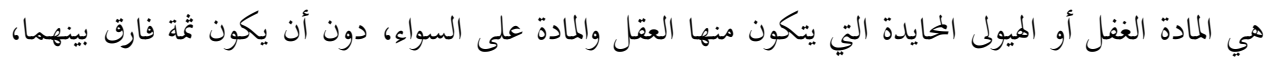

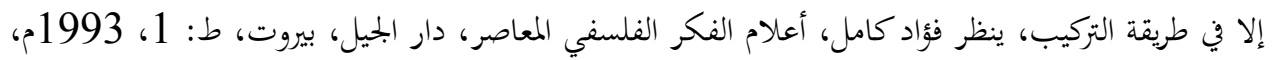


"قوانين المنظور" (")، وهي ذاتا تتكون منها العقول متى تجمعت وفقًا لقوانين علم النفس "قوانين الذاكرة" تدخل هذه العناصر - في جانبها العقلي وضمن غيرها - فيما أسماه "رسل" العلية التذكرية MNEMIC CAUSATION، وهي نوع من الفعل من على بعد تُنتج وفقا لها المعطيات التجريبية صورًا للذاكرة(1).

في هذا الكتاب يشير رسل إلى تحوله عن ذلك النوع من الحتمية الذي اعتقد به في كتابه

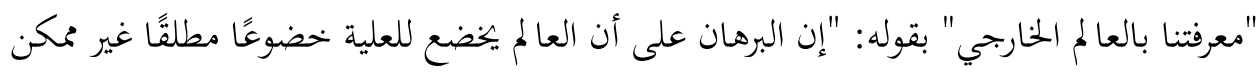

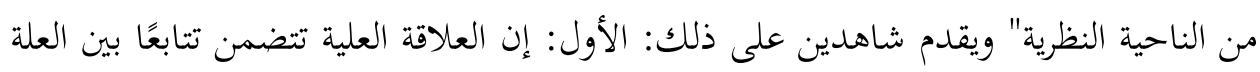

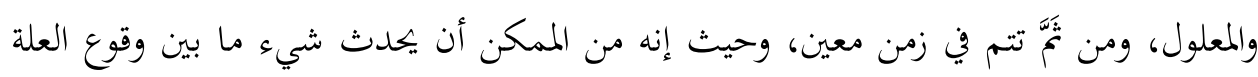

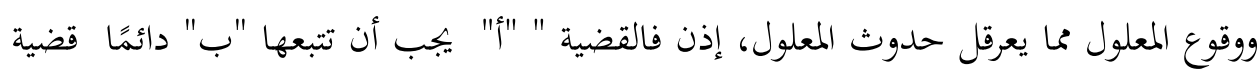

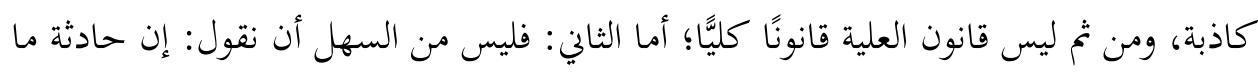

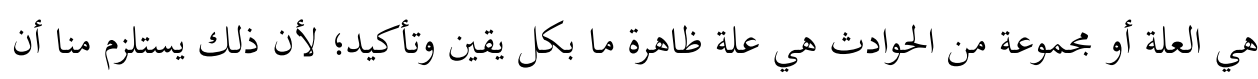

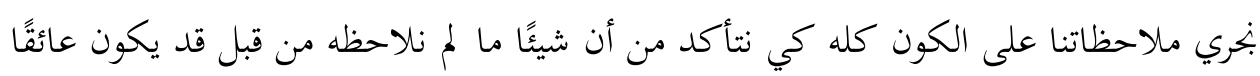

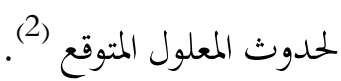
وقد عبر رسل عن سبب تحوله وتطور آرائه في كتابه "النظرة العلمية" "1931م"، حيث ذهب فيه إلى أن نظرية الكوانتم QUANTUM THEORY التي اهتمت بالذرات والإلكترونات

(*) المنظور، يقصد رسل بالمنظور بتميع الحوادث في مكان طبيعي واحد، وقوانين المنظور هي التي تسمح

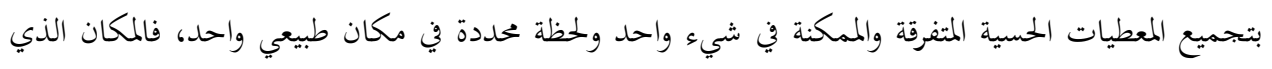

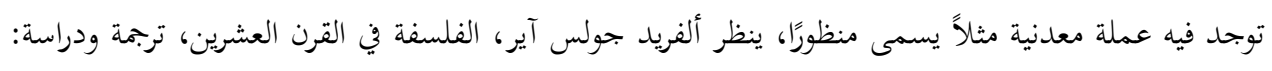

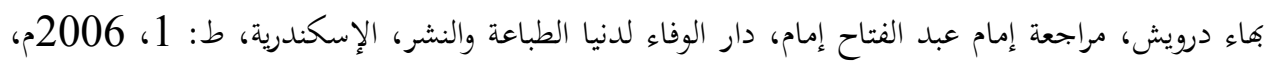

$$
\text { 1- المصدر السابق ، ص } 113 .
$$

2- محمد محمد قاسم، المدخل إلى فلسفة العلوم، ص157 ال1 158 
المنفردة، وكذلك مبدأ اللاحتمية PRINCIPLE INDETERMINACY الذي صاغه "شرودنجر" (") "وهيزنبرج، (") "وشرحه "سيرأرثر إدنجتون" (***) أحدثا انقلابًا سبب إزعاجا للمتعصبين للعلم UNIVERSITY الطبيعي منذ زمن نيوتن، وخاصة بعد التشكيك الذي نال العلية الكونية CAUSALITY ووفقًا لنظرية الكوانتم أصبحت الذرات تتمتع بقدر من الحرية؛ لأن سلوكها لم يعد

(*) أرفين شرودنخر "1887م-1961م"، فيزيائي نمساوي معروف بإسهاماته في ميكانيكا الكم وخصوصًا

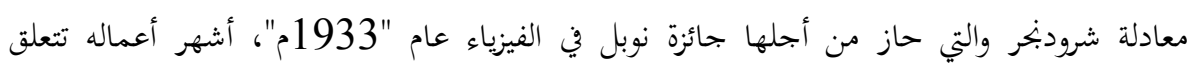

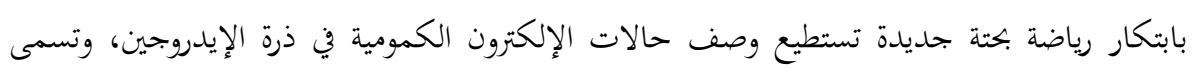
ميكانيكا الكم. استطاع شرودنخر تفسير طيف الإيدروجين عن طريق حل معادئ تلادلته الشهيرة المسماة معادلة شرودنخر وذلك عام "1926م" ميكانيخا ينظر: موسوعة ويكيبيديا الحرة.

(*) ورنر هيزنبرج "1910-1976م"، عالم فيزيائي ألماني، اشتهر باكتشاف تفصيل مبدإ اللايقين في ميكانيكا الكم "1927م"، أسس مع شوردنخر ميكانيكا الكم الحديثة، اعتبر التنبؤات الإحصائية غير القابلة

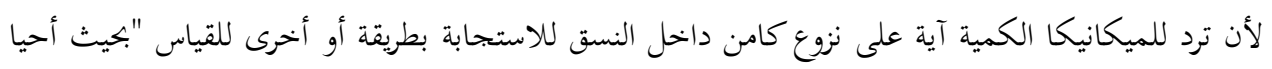

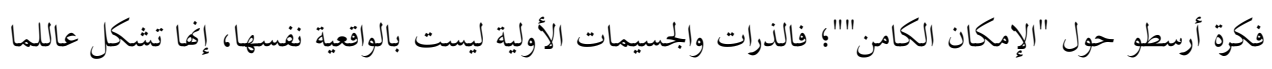

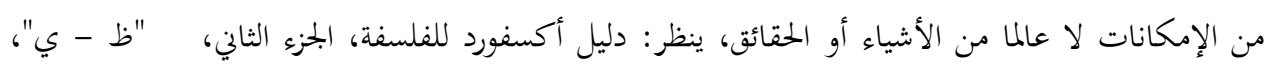

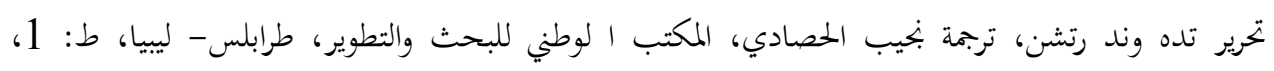
2005م، ص1010.

(السيد آرثر ستانلي إدنختون "1882-1944م"، هو عالم فلك وفيزياء ورياضيات بريطاني، له

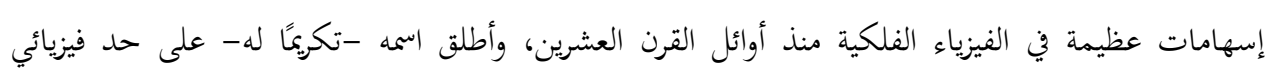

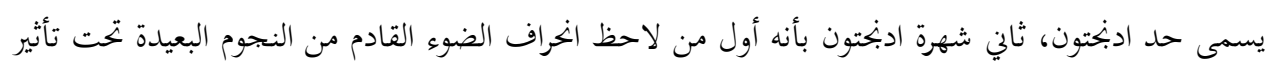

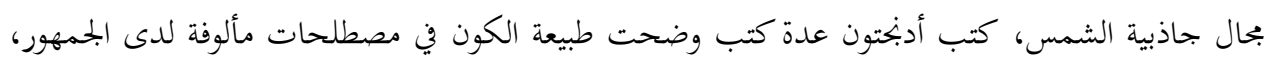

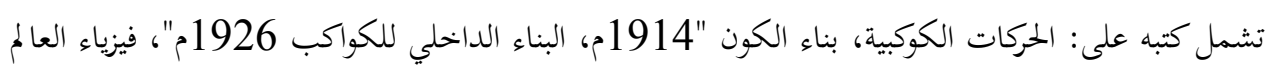
الطبيعي "1928م"، ينظر موسوعة ويكيبيديا الحرة. 
يخضع كليًا لقانون. فضلاً عن ذلك ما كنا نفكر أو نعتقد أنه محدد DEFINTE، اتضح أنه غير

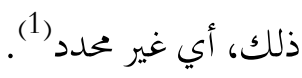

أما مبدأ اللاحتمية فيقول: إن الجزيء A PARTICLE (") إما أن يكون له موضع أو تكون

له سرعة VELOCITY، ولكن لا يمكن أن بخمع بينهما بدقة، فإذا عرفنا موضعه فلا نستطيع أن نخبر عن سرعة انتقاله، وإذا عرفنا سرعة انتقاله، فلا نستطيع تحديد موضعه؛ ومن ثم يستحيل أن نحدد بدقة كلاً من موضع الجزيء وقوة حركته، وهذا التفسير من قبل العلماء أدى إلى اهيار

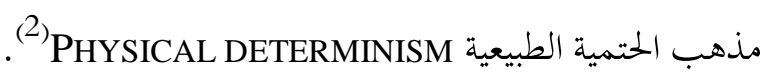
ووفقًا لرسل لا يعني مبدأ اللاحتمية -ما ذهب إليه ادنجتون وعلماء اللاحتمية- أي:

A STATE OF الفوضى ووصول الكون إلى حالة من انعدام أو فقدان النظام الكامل THE END OF THE COMPLETE DISORGANIZATION WORLD بل يعني التحديد الاحتمالي للظاهرة(3). أما عن مفهوم العلية في طوره الأخير عند رسل فيبدو في كتابيه " المعرفة البشرية" "1948م"، و " تطوري الفلسفي" "1959م"؛ حيث يؤكد من جديد أن تصور العلية بمفهومه

1- B, Russell: the Scientific Outlook, ROUTLEDGE, LONDON and NEW YORK, first published, 2001, p.76.

(*) الجزيء: هو أصغر وحدة من المادة الكيميائية النقية يحتفظ بتركيبها الكيميائي وخواصها، علم دراسة

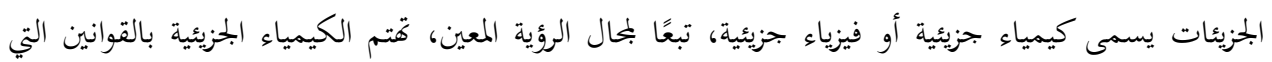
تحكم التفاعلات بين الجزيئات والتي ينتج عنها تكون أو تكسير للروابط الكيميائية، بينما تهتم الفيزياء الجزيئية

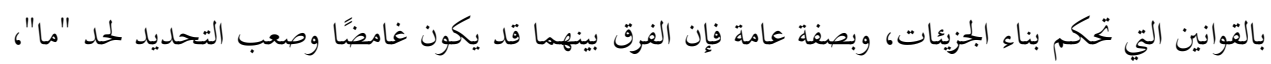

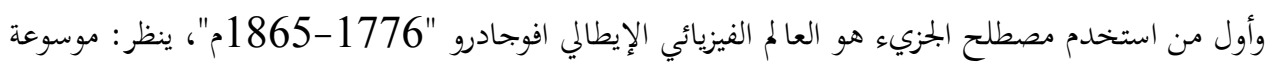
ويكيبيديا الحرة.

2 -.I bid, pp. 70, 76, 81

3 -.I bid, pp. 71,80 
التقليدي " أ- علة، ب- دائمًا" يعد تصورًا بدائيا وغير علمي، وقد حل محله تصور القوانين العلية؛ لأن صورة القانون العلي " أ- علة، ب- قابلة للاستثناء"، أي: يمكن أن تكون لما حالات شاذة، فقد يحدث شيء ما يمنع حدوث ب بسب وجود فاصل زمني بينها وبين "أ"، فمثلاً عندما نقدح عود ثقاب فإنه يشتعل في العادة، إلا أنه قد ينكسر في بعض الأحيان (1). ويذهب رسل إلى أننا ندين للقوانين العلية بمعظم معارفنا، ولكي نتصور وجود الأشياء لا بد أن نتصور دوامها أولاً، وهذا الدوام لا يتم إذا كانت أجزاء الشيء مترابطة متصلة، وعلة اتصالها يسميه رسل " الخط العلي" CAUSAL LINE، ويطلق مصطلح "الخط العلي" على سلسلة من الحوادث تتصف بخاصية، هي أننا لا نستطيع أن نستدل من أية حادثة منها شيئا ما يتعلق بما يجاورها في السلسلة من حوادث، وفائدة الخط العلي تبرير دوام الأشياء والأشخاص، ومن خلال خط عِلّي معين يمكننا أن نلمس ثبات صفات الشيء وبنائه ودوامه (2.) 4. علاقة العِليّة بمصادرات البحث العلمي: لقد عبّر رسّل عن آخر تطور لموقفه بصدد العليّة في كتابه " المعرفة البشرية ميداهما وحدودها" "1948م"، حيث عقد فصلاً عن "مصادرات المعرفة التجريبية"، يقول فيه: إن المنهج العلمي يجب أن يقوم على بعض مصادرات لا يُشتق صدقها من أي بتربة، وإنما يعتقد

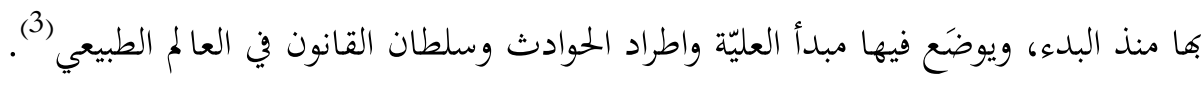

1 - محمد محمد قاسم، المدخل إلى فلسفة العلوم ص167، 168 - 209 168.

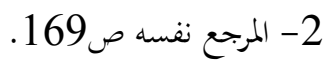

3- محمود فهمي زيدان، من نظريات العلم المعاصر صلم 111. 
ويذهب رسّل إلى أن الاستدلال الاستقرائي بحاجة إلى مبادئ عامّة تمنح درجة تصديق أولية لأنماط معينة من التعميمات(1)، ومسألة تبرير الاستدلال من المقدمات إلى النتيجة يستند بالضرورة إلى مصادرات يطلق عليها رسّل مصادرات المنهج العلمي Postulates of : Scientific Method

\section{أ. مصادرة الثبات التقريبي Postulates of Quasi-permanence:}

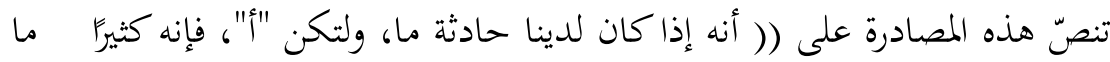
يجدث في زمان بجاور، حادثة ما أخرى في مكان مجاور، مشابهة بلدرجة كبيرة

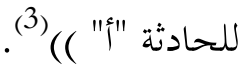

ووظيفة هذه المصادرة هي تقديم وجود المتتابعات المادية، تعتمد على الافتراض القائل

إنه إذا كانت هناك حالتان للشيء نفسه - منفصلتان إلى حدّ كبير في الزمان ومختلفتان كيفًا - مئس مثل الشخص الذي يحمل في الكهولة تشاهمًا ضئيلاً لما كان عليه في طفولته، فإن عملية التغير لمادة ما، تكون تدريجية للغاية، ويمكن أن تُعد مصادرة ردّ تضمن إحلال الأشياء عن طريق الحوادث (4) ماده ماكن.

ويمكن النظر إلى هذه المصادرة على أها قانون عِليّ تقريبًا، ولملا كانت المصادرة تعني

لدى رسّل افتراضًا أوليًا نبدأ به بناء النظريات العلمية ذات النتائج الاحتمالية، لما كانت تعادل

1- حسين علي، فلسفة العلم المعاصر ومفهوم الاحتمال، الدار المصرية السعودية للطباعة والنشر والتوزيع،

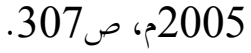

2- ماهر عبدالقادر محمد علي، مشكلات الفلسفة، دار النهضة العبية للطباعة والنشر، بيروت - لبنان،

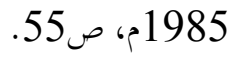

3- المرجع السابق. 4- - حسين علي، فلسفة العلم المعاصر ومفهوم الاحتمال ص308. 302 
القانون العليّ تقريبًا في درجة الاحتمال التي تضفيها، فإن القانون العليّ - هو الآخر - يُعد افتراضًا أوليَّا(1).

Postulates of Separable بلب.مصادرة الخطوط العِيّة القابلة للانفصال

\section{:Causal Lines}

تنصّ هذه المصادرة على أنه ((كثيرًا ما يكون من الممكن أن تؤَلف سلسلة من

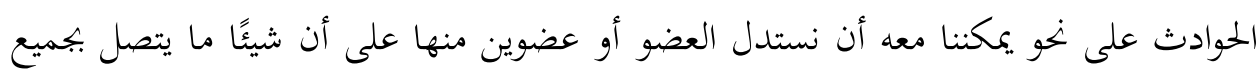
(الأعضاء () (الحواد علئ (2)

ويقصد رسّل بقوله -في المصادرة- "سلسلة من الحوادث تأتي على نحو معين"، هو

الخطط العِلِّي، أما الذي يجعل الاستدلال أمرًا ممكنًا فهو القانون العِلِّي، ويصرّح رسل في كتابه "تطوري الفلسفي" بأن هذه المصادرة تُعد امتدادًا للمصادرة الأولى من حيث استخدامها

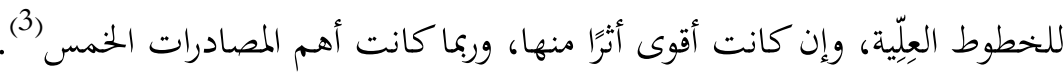

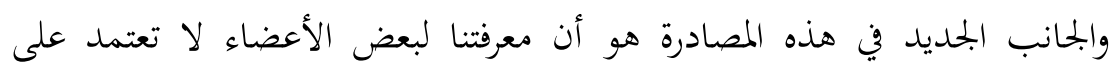

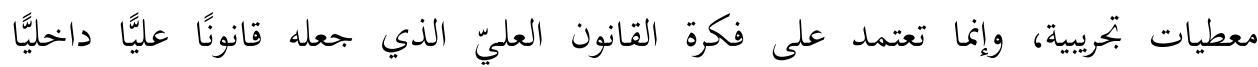
Intrinsic أعضاء السلسلة غير الخاضعة للملاحظة، دون الرجوع إلى أي شيء آخر في العالم (4).

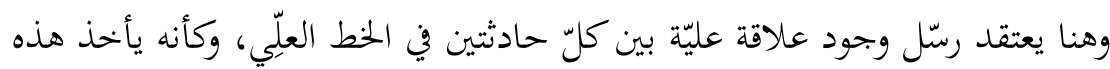

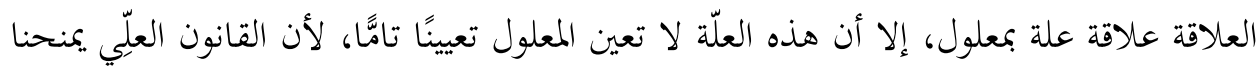
القدرة على التنبؤ الاحتمالي، على عكس المفهوم التقليدي للعليّة، وخير مثال على استخدام هذه المصادرة هي فكرة الحركة، حيث يحتفظ الشيء بكويته وذاتيته مع تغيير موضعه، إذ بفضل

1 - محمد محمد قاسم، المدخل إلى فلسفة العلوم ص174.

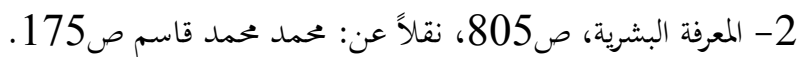
3- المرجع السابق.

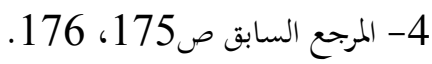


دوام موجات الصوت وموجات الضوء يمكن لعمليتي السمع والإبصار أن يقدما لنا معرفة عن حوادث معينة قربت أم بعدت (1).

Postulate of Spatio - Temporal مصادرة الاتصال الزماني والمكاني

:Continuity

تنصّ هذه المصادرة على أنه (( حينما توجد رابطة عليّة بين حادثتين ليستا

منفصلتين؛ فإنه يجب أن توجد روابط متوسطة في حلقات السلسلة العليّة، يكون كلّ منها متصلاً بالتالي، أو أنه توجد عملية متصلة بالمعنى الرياضي ()) (2).

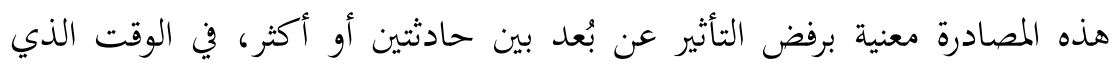
نفترض فيه الخطوط العليّة افتراضًا مُسبقًا، ويبدو أهما تسمح لنا بأن نعتقد وجود أشياء طبيعية

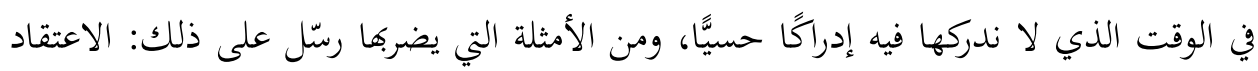

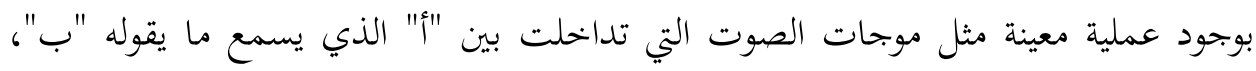

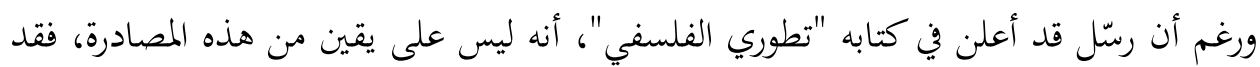
تُرد إلى تحصيل حاصل، طالما أن ترتيب الحوادث الزمكانية أمر يتوقف على العليّة، وطالما أن

$$
\text { الزمكان هو أمر استدلالي (3). }
$$

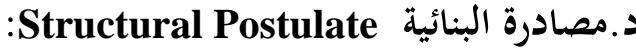

تنص هذه المصادرة على أنه (( عندما يكون هناك عدد من الحوادث المتشاهمة من حيث البنية والتركيب، ومرتبة في حيّز مكاني، بحيث لا تكون هذه الحوادث متباعدة، فإنه عادةً ما تكون هذه الحوادث منتمية إلى خطوط عليّة صادرة عن حادثة لما، التركيب نفسه في هذا

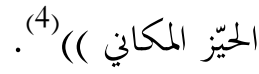

$$
\begin{aligned}
& \text { 1- 2 - المرجع السابق ص176. } \\
& \text { 2- ماهر عبدالقادر محمد علي، مشكلات الفلسفة ص55. }
\end{aligned}
$$

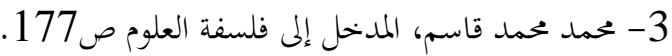

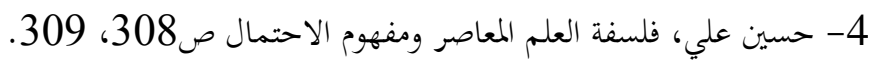


تعد هذه المصادرة تطويرًا لقوانين المنظور؛ لأها تؤكد ضيق المسافات بين الحوادث التي تضمن انتظام الحوادث حول مركز معين، ومن ثم ينفي التأثير عن بُعلد. ومن الأمثلة على هذه

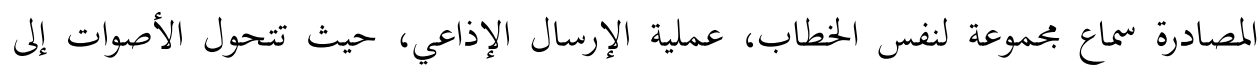

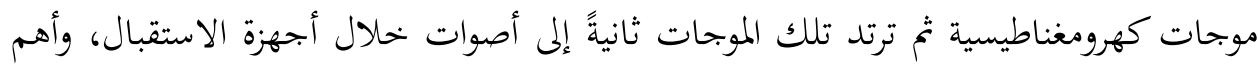
المبادئ التي تقوم عليها كلّ الأمثلة البنائية في العلم والحياة اليومية على السواء، هو مبدأ الثبات Persistence Principle فالبناء يتضمن الإشارة إلى الثبات النسبي للإدراك الحسّي لدى الفرد، ولدى بحموعة من الناس المختلفين بتحاه موضوع واحد في ظروف متعددة).

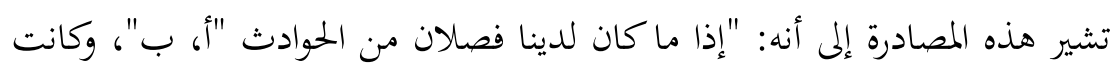

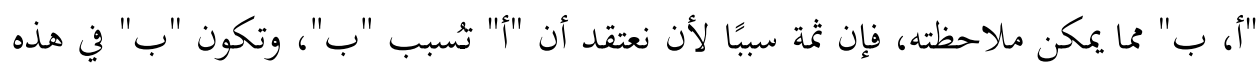
الحالة محتملة الحدوث (2). فمثلاً من خلال ملاحظتي الذاتية على أن "أ" بوصفها فكرة أو شعورًا، علّة

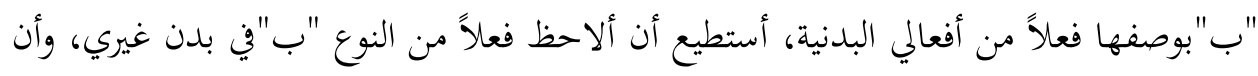
هذا الفعل مرتبط بعقل غيري "فكرة، أو شعور من النوع "أ" " غير الْمُلاحظ، وبالتالي نستطيع

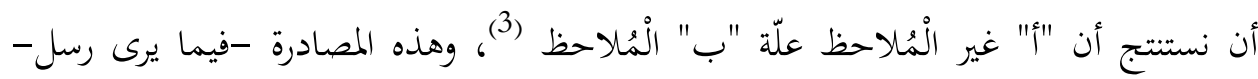

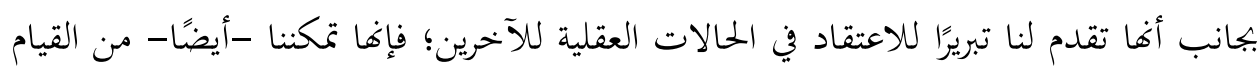
باستدلالات أخرى مثل: الأجسام التي تعطينا الإحساس بالصلابة، تظل على صلابتها ولو لم لمالم

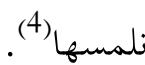

1 - محمد محمد قاسم، المدخل إلى فلسفة العلوم ص 179، 180 - 180.

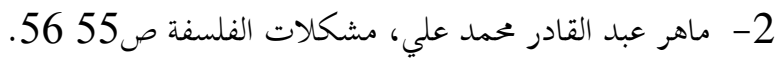

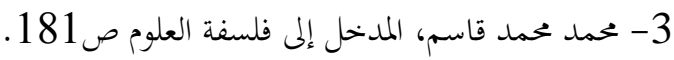

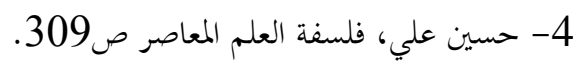




\section{الخاتمة:}

بعد هذا العرض للدليل الاستقرائي بين "ديفيد هيوم" و "برتراندرسل" يمكن لي أن أُجمل أهم ما توصلت إليه من نتائج فيما يأتي: 1- رفض كل من هيوم ورسل العلاقة الضرورية للعلية "العلة نفسها، المعلول نفسه"، وقالا بإن التنابع بين الحوادث تتابع احتمالي؛ لأنه لا برهان لإثبات الاطراد بحريبيّا؛ أي ليس تي

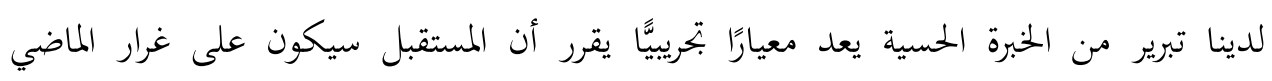
والحاضر.

2- ابته هيوم في تفسيره للدليل الاستقرائي ابحاهًا نفسيًا، فالرابطة العلية الضرورية من الانطباع الحسي، والفكرة تقوم على أساس مبدأ "نشوء العادة"، وهي رابطة مكتسبة من التجربة، ولكنها ذاتية من صنع رابطة المخيلة، وليست في الأشياء ولا بين الأشياء. 3- ولما كانت الرابطة الضرورية عند هيوم "ذهنية" وليست "منطقية موضوعية" فإنه

سيترتب على ذلك أن يتحول اليقين إلى احتمال؛ لأن الأساس النفسي الذي يقوم عليه الإدراك هو الانطباع الحسي الذي دونه لا تكون الفكرة ذات معنى. 4- على عكس هيوم ابته رسل في تفسيره الدليل الاستقرائي ابحاهًا منطقيًّا، حيث رأى ضرورة التسليم بالاستقراء على أنه مبدأ أولي سابق على التجربة، وجَعَله سابقًا على العليّة لكي يضمن افتراض القوانين العليّة، ودوام استمرارها في المستقبل. 
5- تعريف رسّل للعليّة وللقانون العليّ، هو تعريف الحتمية المعتدلة نفسه، إذ أنه

أخذ العلاقة بين الحادثة وظروف حدوثها علاقة علة بمعلول، وبالتالي ردّ الحتمية إلى العليّة، على عكس العلماء المعاصرين الذين رأوا احتواء العليّة في الحتمية. كما جعل القانون العليّ احتماليًا، ومن تََّّ أصبح الاستدلال احتماليَّا يقترب من اليقين، ويعني الدرجة العالية من التصديق. 6- لعبت العليّة دورًا مهمَّا في مصادرات المنهج العلمي؛ حيث جعل رسّل المصادرات تبريًا للاستدلال الاستقرائي، ونفيًا لفكرة التأثير عن بُعد، فكل مصادرة أيتِ بها لتؤكد سابقاتحا؛ فالمصادرة الرابعة "البنائية"تضمنت كل الأفكار التي تضمنتها المصادرات السابقة عليها، وجاءت دعمًا لنظرية الخطوط العليّة وللقانون العليّ بوصفه احتماليّّا، وتأكيدًا على الاتصال الزمكاني، أما المصادرة الخامسة فجاءت توضيحًا للدور المعرفي لفكرة العلّة والمعلول لدى الآخرين. 


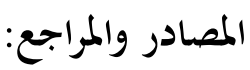

$$
\text { أولاً: المصادر: }
$$

1- الحسين بن علي بن سينا، النجاة، تنقيح وتقديم: د. ماجد فخري، دار الآفاق الجديدة،

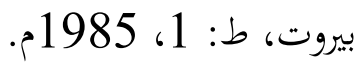
2- ألفريد جولس آير، الفلسفة في القرن العشرين، ترجمة ودراسة: بهاء درويش، مراجعة: إمام

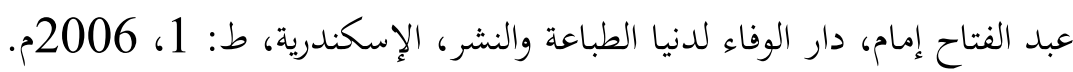

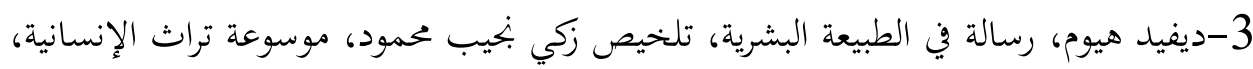

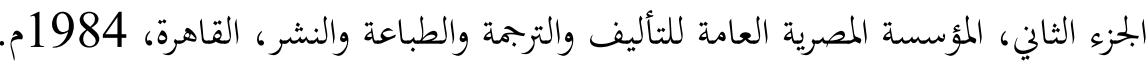
ثانيًا: المراجع: أموان: 1- أحمد خورشيد النوره جي، مفاهيم في الفلسفة والاجتماع، دار الشؤون الثقافية، بغداد، 1990

2- جعفر آل ياسين، المنطق السينوي، دار الآفاق الجديدة، بيروت، 1983م.

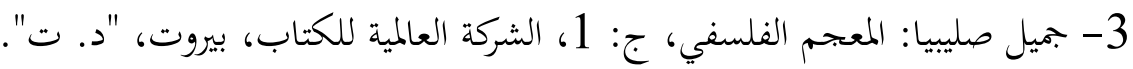
4- حسن حنفي، مقدمة في علم الاستغراب، الدار الفنية للنشر والتوزيع، 1991م. 5- حسين علي: فلسفة العلم المعاصر ومفهوم الاحتمال، الدار المصرية السعودية للطباعة

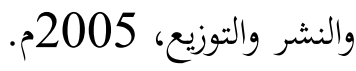

6- زكريا إبراهيم، دراسات في الفلسفة المعاصرة، مكتبة مصر، القاهرة، ط: 1، 1968م، 1968. 7- زكي بنيب محمود: المنطق الوضعي، ج: 2، "في فلسفة العلوم" مكتبة الأبحلو المصرية،

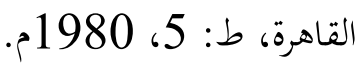

8- فؤاد كامل، أعلام الفكر الفلسفي المعاصر، دار الجيل، بيروت، ط: 1ه، 1ه، 1993م.

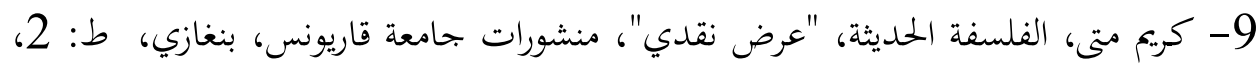


10- ماهر عبد القادر محمد، فلسفة العلوم "المشكلات النظرية والتطبيق"، دار المعرفة الجامعية، الإسكندرية، 1997م.

11 - محمد أحمد السرياقوسي، التعريف بمناهج البحث المنطقي، دار الثقافة للنشر والتوزيع، القاهرة، 1995م.

12- محمد فتحي الشنيطي، المعرفة، دار الثقافة للطباعة والنشر، القاهرة، 1981م. 13- محمد محمد طاهر آل شبير، نقد المذهب التجريبي، دار ومكتبة الهلال، بيروت، 1987 14- محمد محمد قاسم، المدخل إلى فلسفة العلوم، دار المعرفة الجامعية، الإسكندرية، 1996

15- محمود فهمي زيدان، من نظريات العلم المعاصر إلى المواقف الفلسفية، دار النهضة العربية للطباعة والنشر، بيروت - لبنان، 1982م. 16- يمنى طريف الخولي: العلم والاغتراب والحرية، الهيئة المصرية العامة للكتاب، القاهرة، بروبا

ثالثًا: المصادر الأجنبية: - مانية

1- B, Russell: the problems of philosophy Oxford University Press London, 2001

2- B, Russell: the Scientific Outlook, ROUTLEDGE, LONDON and NEW YORK, first published, 2001. 